DOI: 10.12957/demetra.2016.22384

\title{
Desenvolvimento, composição centesimal e análise sensorial de barras à base de grãos de quinoa (Chenopodium quinoa willd.) submetidos a diferentes
} tratamentos térmicos

\author{
The development, the chemical composition and the sensory analysis of quinoa bars \\ (Chenopodium quinoa willd) subjected to different thermal treatments
}

\author{
Marjana Radünz' \\ Júlia Nickel ${ }^{2}$ \\ Márcia Arocha Gularte² \\ Elizabete Helbig² \\ 1 Universidade Federal de Pelotas, Faculdade de \\ Nutrição, Departamento de Nutrição. Pelotas-RS, \\ Brasil. \\ ${ }^{2}$ Universidade Federal de Pelotas, Faculdade \\ de Nutrição, Programa de Pós-Graduação em \\ Nutrição e Alimentos. Pelotas-RS, Brasil.

\section{Correspondência / Correspondence} \\ Júlia Nickel \\ Faculdade de Nutrição, Programa de \\ Pós-Graduação em Nutrição e Alimentos, \\ Universidade Federal de Pelotas \\ Rua Gomes Carneiro, $n^{0}$ l, CEP: 96010-610, \\ Pelotas-RS, Brasil. \\ E-mail: julianickel@gmail.com
}

\section{Resumo}

Objetivos: Considerando o elevado valor nutricional dos grãos de quinoa, com proteína composta por todos os aminoácidos essenciais, objetivou-se desenvolver barras de cereais elaboradas com o grão após dois processamentos térmicos, avaliar a composição centesimal e verificar a preferência entre as barras por análise sensorial. Material e métodos: As barras foram elaboradas com quinoa submetidas ao processo de hidratação em água e torração. Realizou-se composição centesimal (umidade, cinzas, fibra bruta, proteína, lipídeos e carboidratos) dos grãos e barras de quinoa. Assim como análise sensorial para verificação da preferência entre as barras, por meio de escala hedônica de 7 pontos e intenção de compra por escala de 5 pontos. Resultados: Os teores de lipídios, fibra bruta, cinzas e carboidrato dos grãos de quinoa sofreram variações após os processamentos térmicos. Entre as barras houve diferença nos teores de proteína, cinzas e carboidratos. $\mathrm{Na}$ análise sensorial, a barra contendo grãos de quinoa torrados foi a preferida, obtendo bom índice de aceitabilidade (85\%), enquanto a barra contendo grãos de quinoa hidratados apresentou um índice menor $(66,34 \%)$, não sendo aceita, principalmente por ter apresentado textura amolecida. $\mathrm{O}$ mesmo ocorreu na intenção de compra, em que os consumidores demonstraram que provavelmente comprariam a barra com grãos torrados e talvez comprariam a com grãos hidratados. Conclusão: A barra de cereal elaborada com grãos de quinoa torrados é a melhor formulação 
para desenvolvimento do produto, que apresenta viabilidade para ser comercializado, pois obteve bom índice de aceitabilidade.

Palavras-chave: Valor nutritivo. Lanches. Proteínas na dieta. Alimentos. Chenopodium quinoa.

\begin{abstract}
Objective: Considering the high nutritional value of quinoa grain, with protein composed by all essential amino acids, this study aimed to develop cereal bars elaborated with this grain after two different thermal processing, to evaluate the chemical composition and to verify the preference between the bars using a sensory analysis. Material and methods: The bars were prepared with quinoa submitted to hydration process in water and toasting process. It was performed the chemical composition (moisture, ash, crude fiber, protein, lipids and carbohydrates) of the grains and quinoa bars. The sensory analysis for verification of preference between the bars was performed by hedonic scale of 7 points and purchase intent by 5 -point scale. Results: The lipid, crude fiber, ash and carbohydrate contents of quinoa grains had variations after thermal processing. Between the bars, there were significant differences in protein, ash and carbohydrates amount. In the sensorial analysis, the bar containing toasted quinoa grains was preferred, with good acceptability index (85\%), while the bar containing hydrated quinoa grains presented a lower rate (66.34\%), not being accepted, mainly because of its softened texture. The same occurred in purchase intent, which consumers showed that would probably buy the bar elaborate with toasted grains and would maybe buy the bar containing hydrated grains. Conclusion: The cereal bar produced with toasted quinoa grains is the best formulation for product development, which has viability to be commercialized, as it obtained a good acceptability index.
\end{abstract}

Key words: Nutritive value. Snacks. Dietary proteins. Food. Chenopodium quinoa.

\title{
Introdução
}

A crescente busca dos indivíduos por um estilo de vida saudável desperta interesse no desenvolvimento de produtos nutritivos, como as barras de cereais. Esse alimento apresenta praticidade, pois pode ser consumido em qualquer lugar e a qualquer hora do dia, assim como características sensoriais agradáveis. ${ }^{1}$ Em função disso, pode ser utilizado como veículo para inclusão de ingredientes com alegação funcional no mercado consumidor. ${ }^{2}$ 
As barras são elaboradas a partir de uma mistura de cereais, constituindo fonte de vitaminas, sais minerais, fibras, proteínas e carboidratos. Vários ingredientes podem ser introduzidos nessas barras com o objetivo de aumentar seu valor nutritivo e trazer maiores benefícios à saúde do consumidor, sendo a quinoa (Chenopodium quinoa Willd.) um desses componentes. ${ }^{3}$ A quinoa é um pseudocereal de elevada importância nutricional, destacando-se a qualidade de sua proteína, que possui todos os aminoácidos essenciais, o que a diferencia dos cereais tradicionais, deficientes nesses aminoácidos. Outro fator favorável e diferencial é a ausência de proteínas que contenham glúten, podendo ser consumida por portadores de doença celíaca e utilizada na produção de diversos alimentos direcionados para este grupo da população., ${ }^{4,5}$

Esse grão apresenta em sua composição vitaminas C, E, complexo B; minerais como cálcio, potássio, ferro, magnésio, manganês e fósforo; além de isoflavonas e lipídios de boa qualidade (linoleico e linolênico), que proporcionam à quinoa consideráveis propriedades antioxidantes. ${ }^{6}$ Os grãos possuem também ecdisteroides, que são metabólitos secundários da planta e auxiliam na redução da glicemia, colesterolemia e desempenham efeitos anabólicos ligados ao estímulo da síntese proteica em geral. ${ }^{7}$

Porém, a quinoa apresenta em sua camada externa compostos glicosídeos denominados saponinas, que lhe conferem sabor amargo. As saponinas são facilmente reduzidas por métodos úmidos (lavagens em água fria) ou secos (torração e abrasão). ${ }^{8}$

No Brasil o consumo de quinoa ainda é limitado devido ao alto custo do grão importado, desconhecimento da população, hábitos e costumes tradicionais de outros cereais e baixa disponibilidade de cultivares adaptadas às condições locais. ${ }^{8}$ Sendo este grão de alto teor nutricional, seu uso em diversos produtos de consumo habitual, como pães, biscoitos e barras de cereal, torna-se interessante. Nesse contexto, para que se avalie a aceitação da incorporação de novos ingredientes a produtos tradicionais, é de suma importância a realização de análise sensorial.

A análise sensorial consiste em um método de avaliação que pode ser utilizado para verificar a aceitação de alimentos no mercado, através do qual é possível promover o desenvolvimento de novos produtos levando em consideração as preferências individuais do consumidor. Para isso, são realizadas pesquisas especificamente direcionadas às preferências do público-alvo em questão., ${ }^{9,10}$ Ela é baseada nas respostas dos julgadores às sensações resultantes de estímulos, o que leva à interpretação das propriedades características do produto. ${ }^{11}$

Considerando o consumo de barras de cereais, a praticidade do produto e o alto valor nutricional do grão de quinoa, objetivou-se elaborar barras de cereais à base de quinoa submetidas a diferentes processos térmicos (hidratação e torração); sua composição centesimal, avaliando alterações em função desses processos; e a preferência entre as barras de cereal por meio de análise sensorial. 


\section{Material e Métodos}

Apresentação e processamento da amostra

As amostras de grãos de quinoa foram adquiridas no comércio da cidade de Rio Grande-RS. Os grãos foram lavados e friccionados com as mãos em água corrente durante 15 minutos para a redução das saponinas de sua camada externa e posteriormente foram secos em estufa a $40^{\circ} \mathrm{C}$ durante $12 \mathrm{~h}$.

Após, os grãos foram divididos em dois grupos. O primeiro foi hidratado em água (proporção 1:2) a $60^{\circ} \mathrm{C}$ durante 30 minutos e o segundo foi torrado em chapa de aquecimento a $140^{\circ} \mathrm{C}$ durante 7 minutos, momento em que os grãos atingiram a coloração dourada.

Avaliação centesimal dos grãos de quinoa

As análises de composição centesimal foram realizadas no Laboratório de Pós-Colheita, Industrialização e Qualidade de Grãos da Universidade Federal de Pelotas (UFPel). Os grãos de quinoa hidratados e torrados foram avaliados quanto à umidade, cinzas, fibra bruta, proteína, lipídeos e carboidratos segundo o Instituto Adolfo Lutz," apresentando como controle os grãos crus.

Desenvolvimento das barras de cereal

As barras de cereal contendo quinoa foram elaboradas no laboratório de Técnica Dietética da Faculdade de Nutrição da UFPel. Os ingredientes utilizados na preparação foram pesados em balança eletrônica e estão descritos na Tabela 1 . 
Tabela 1. Ingredientes da barra de cereal à base de quinoa. Pelotas-RS, 2014.

\begin{tabular}{lc}
\hline \multicolumn{1}{c}{ Ingrediente } & Quantidade $\%$ \\
\hline Quinoa (hidratada / tostada) & 20 \\
Farinha de quinoa crua & 20 \\
Pêssego desidratado & 5,5 \\
Uva-passa & 5,5 \\
Castanha do Brasil & 12 \\
\hline Total de ingredientes secos & 63 \\
\hline Açúcar mascavo & 7,5 \\
Xarope de glicose & 26 \\
Água & 3,5 \\
\hline Total de agentes ligantes & 37 \\
\hline
\end{tabular}

Para o desenvolvimento, preparou-se uma mistura composta pelos ingredientes secos (grãos de quinoa, farinha de quinoa, pêssego desidratado, uva passa e castanha do Brasil) e sobre eles foi adicionada uma calda elaborada com açúcar mascavo, xarope de glicose e água, aquecida em banho-maria. Essa mistura foi colocada em fôrma de alumínio e submetida a forno elétrico com temperatura de $150^{\circ} \mathrm{C}$ por 30 minutos. Após esse processo, as barras foram cobertas com filme plástico e armazenadas sobre refrigeração no laboratório por um dia para análise sensorial.

\section{Avaliação centesimal das barras de cereal}

As barras de quinoa hidratadas e torradas também foram avaliadas quanto à composição centesimal (umidade, cinzas, fibra bruta, proteína, lipídeos e carboidratos) segundo o Instituto Adolfo Lutz. ${ }^{11}$

O valor energético total (VET em kcal/100 g) das barras e grãos de quinoa foi obtido através da equação VET $=(\mathrm{C} \times 4)+(\mathrm{A} \times 4)+(\mathrm{B} \times 9)$, sendo C: carboidratos, A: proteína total e B: lipídios. ${ }^{12}$

\section{Análise sensorial das barras de cereal}

A análise sensorial das barras de cereal contendo quinoa foi desenvolvida no Laboratório de Alimentação Coletiva da Faculdade de Nutrição da UFPel por 110 provadores não treinados 
recrutados no local (alunos, professores e servidores). Para a avaliação sensorial das formulações, foi utilizado o teste de preferência, com escala hedônica de 7 pontos, variando de 7 - gostei muito a 1 - desgostei muito. ${ }^{13}$ Foi verificada também a intenção de compra do produto pelo consumidor, utilizando escala de 5 pontos, variando de 5 - certamente compraria a 1 - certamente não compraria.

O índice de aceitabilidade das barras de cereal foi obtido através da fórmula IA $(\%)=\mathrm{A} \times 100 /$ B, sendo A: nota média obtida para a amostra e B: nota máxima dada para a amostra. Considerase como aceito o produto que apresentar IA $\geq 70 \%{ }^{13}$

No momento do teste, foram ofertados juntamente $10 \mathrm{~g}$ de cada barra de cereal (grão hidratado e grão torrado) dispostas em pratos plásticos descartáveis na cor branca, identificados por números de três dígitos aleatórios.

Todos os participantes aceitaram participar da avaliação, assinando o Termo de Consentimento Livre e Esclarecido, previamente aprovado pelo Comitê de Ética em Pesquisa da UFPel, no 452.476.

\section{Análise Estatística}

Os resultados foram avaliados em software STATISTICA (versão 7.0), empregando-se análise de variância (ANOVA) com nível de significância de 5\% seguido por teste de Tukey nas análises físico-químicas dos grãos de quinoa processados. Para comparação entre as médias da análise físico-química das barras de cereal e avaliação sensorial, foi utilizado teste t Student. Empregou-se teste de frequência para escalas hedônicas e intenção de compra.

\section{Resultados}

\section{Composição centesimal dos grãos e barras de cereal}

Os resultados da análise centesimal dos grãos de quinoa crus e após os processamentos de torração e hidratação evidenciaram diferença significativa $(\mathrm{p}<0,05)$ no teor de lipídios entre os três tratamentos. O teor de fibras foi significativamente menor para os grãos torrados em comparação aos hidratados e crus, já o teor de cinzas foi menor nos grãos hidratados e o de carboidratos, maior nos grãos crus (Tabela 2).

Com relação à composição centesimal das barras de cereal contendo quinoa, a elaborada com grãos hidratados apresentou teor significativamente maior de proteína em comparação com a barra elaborada com grãos torrados, já o teor de cinzas e carboidratos foi maior para a barra com grãos torrados (Tabela 2). 
Tabela 2. Composição centesimal (\%) em base seca dos grãos de quinoa antes e após processamento e das barras de cereal de quinoa com grão torrado e hidratado. Pelotas-RS, 2014.

\begin{tabular}{ccccc}
\hline & Grão cru & Grão torrado & Grão hidratado & $\mathrm{p}$ \\
\hline Proteína & $13,95 \pm 0,55^{\mathrm{a}}$ & $14,11 \pm 0,44^{\mathrm{a}}$ & $14,54 \pm 0,34^{\mathrm{a}}$ & 0,321 \\
Lipídios & $4,84 \pm 0,37^{\mathrm{c}}$ & $6,83 \pm 0,08^{\mathrm{b}}$ & $7,57 \pm 0,09^{\mathrm{a}}$ & $<0,0001$ \\
Fibra bruta & $2,70 \pm 0,05^{\mathrm{a}}$ & $2,26 \pm 0,09^{\mathrm{b}}$ & $2,61 \pm 0,14^{\mathrm{a}}$ & 0,0048 \\
Cinzas & $2,01 \pm 0,14^{\mathrm{a}}$ & $2,07 \pm 0,10^{\mathrm{a}}$ & $1,68 \pm 0,04^{\mathrm{b}}$ & 0,0065 \\
Carboidrato & $76,51 \pm 0,85^{\mathrm{a}}$ & $74,73 \pm 0,66^{\mathrm{b}}$ & $73,60 \pm 0,33^{\mathrm{b}}$ & 0,0204 \\
\hline Total de kcal/100g & 405,34 & 416,80 & 420,66 & \\
\hline & Barra de cereal & Barra de cereal & & $\mathrm{p}$ \\
\hline grão torrado & grão hidratado & & 0,0034 \\
Proteína & $7,24 \pm 0,28^{\mathrm{d}}$ & $10,35 \pm 0,83^{\mathrm{e}}$ & & 0,2732 \\
Lipídios & $11,01 \pm 0,40^{\mathrm{d}}$ & $10,67 \pm 0,25^{\mathrm{d}}$ & & 0,7006 \\
Fibra bruta & $2,50 \pm 0,05^{\mathrm{d}}$ & $2,46 \pm 0,16^{\mathrm{d}}$ & & $<0,0001$ \\
Cinzas & $2,04 \pm 0,02^{\mathrm{d}}$ & $1,72 \pm 0,01^{\mathrm{e}}$ & & 0,0075 \\
\hline Carboidrato & $77,20 \pm 0,14^{\mathrm{d}}$ & $74,80 \pm 0,82^{\mathrm{e}}$ & & \\
\hline
\end{tabular}

Total de kcal/lo0g 436, $92 \quad 4362$

Resultados expressos em base seca (\%). Umidade grão cru $=10,08 \pm 0,05$; grão tostado $=5,87 \pm 0,26$; grão hidratado $=60,53 \pm 0,05$; barra de cereal grão torrado $=14,35 \pm 0,11$; barra de cereal grão hidratado $=27,55$ $\pm 0,83$.

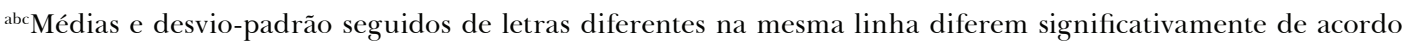
com análise por ANOVA seguido por teste de Tukey $(\mathrm{p} \leq 0,05)$.

deMédias e desvio-padrão seguidos de letras diferentes na mesma linha diferem significativamente de acordo com teste t Student $(\mathrm{p} \leq 0,05)$.

\section{Análise sensorial}

A análise sensorial foi realizada com 110 julgadores, com idade variando de 18 a 57 anos e a maioria mulheres $(85 \%)$.

A barra contendo quinoa torrada foi preferida, obtendo bom índice de aceitabilidade de $85 \%$ em relação à hidratada, que apresentou $66,3 \%$ de aceitabilidade. Isso indica que a barra contendo 
grãos hidratados não foi aceita, pois para isso o alimento deve apresentar índice superior a $70 \% .^{13}$ Esse resultado pode ser demonstrado através da frequência das notas pelos consumidores a cada atributo avaliado (cor, textura e sabor), apresentadas nas Figuras 1, 2 e 3, respectivamente. Nota-se que em todos os atributos as maiores notas se concentraram na barra contendo grãos torrados, enquanto para a barra contendo grãos hidratados foram atribuídas sobretudo as notas menores e intermediárias. A maior discrepância foi observada no atributo de textura, em que a barra contendo grãos hidratados obteve principalmente notas baixas, que se concentraram em 'desgostei moderadamente' e 'desgostei ligeiramente' (Figura 2).

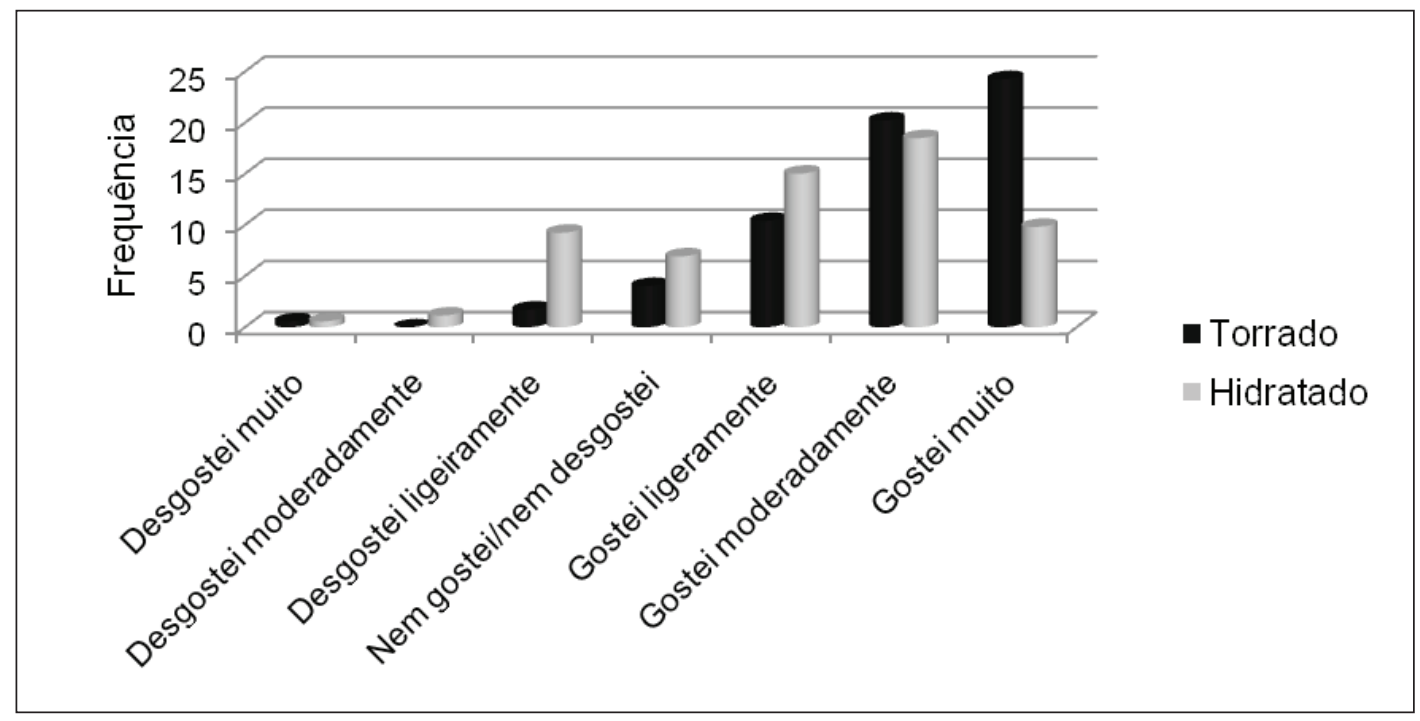

Figura 1. Distribuição da frequência dos valores hedônicos para o atributo cor da barra de cereal contendo grão de quinoa torrado e hidratado. Pelotas-RS, 2014. 


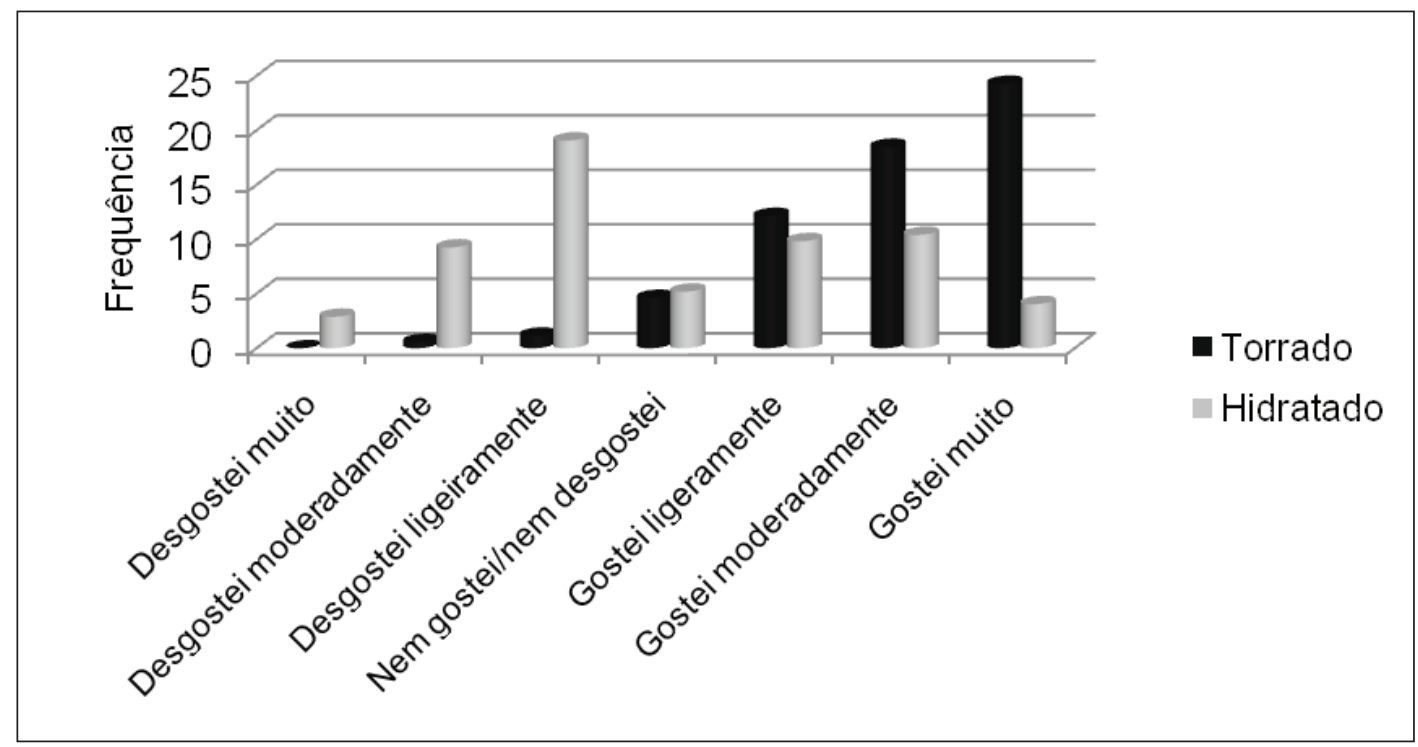

Figura 2. Distribuição da frequência dos valores hedônicos para o atributo textura da barra de cereal contendo grão de quinoa torrado e hidratado. Pelotas-RS, 2014.

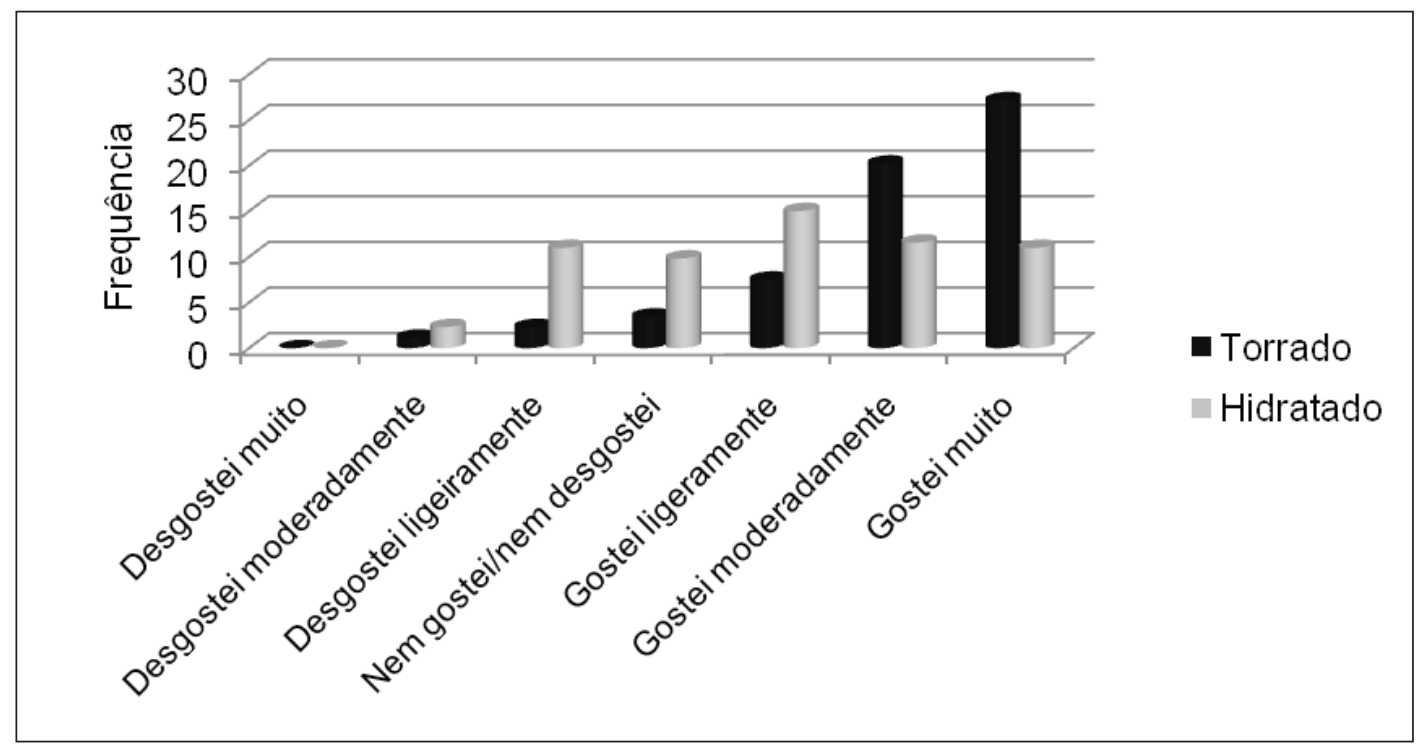

Figura 3. Distribuição da frequência dos valores hedônicos para o atributo sabor da barra de cereal contendo grão de quinoa torrado e hidratado. Pelotas-RS, 2014. 
Quanto à intenção de compra, as barras de cereal contendo quinoa torrada e hidratada

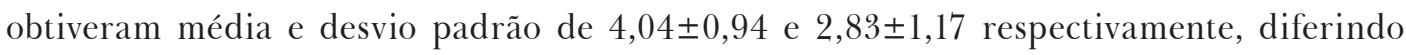
significativamente entre si $(\mathrm{p}<0,05)$. Esse resultado indica que os consumidores provavelmente comprariam a barra elaborada com grãos torrados e talvez comprariam a elaborada com grãos hidratados, comprovando a preferência pela primeira. Isso pode ser visualizado na Figura 4, em que a barra de cereal contendo grãos de quinoa torrados recebeu as maiores notas, enquanto a contendo grãos hidratados recebeu notas mais baixas.

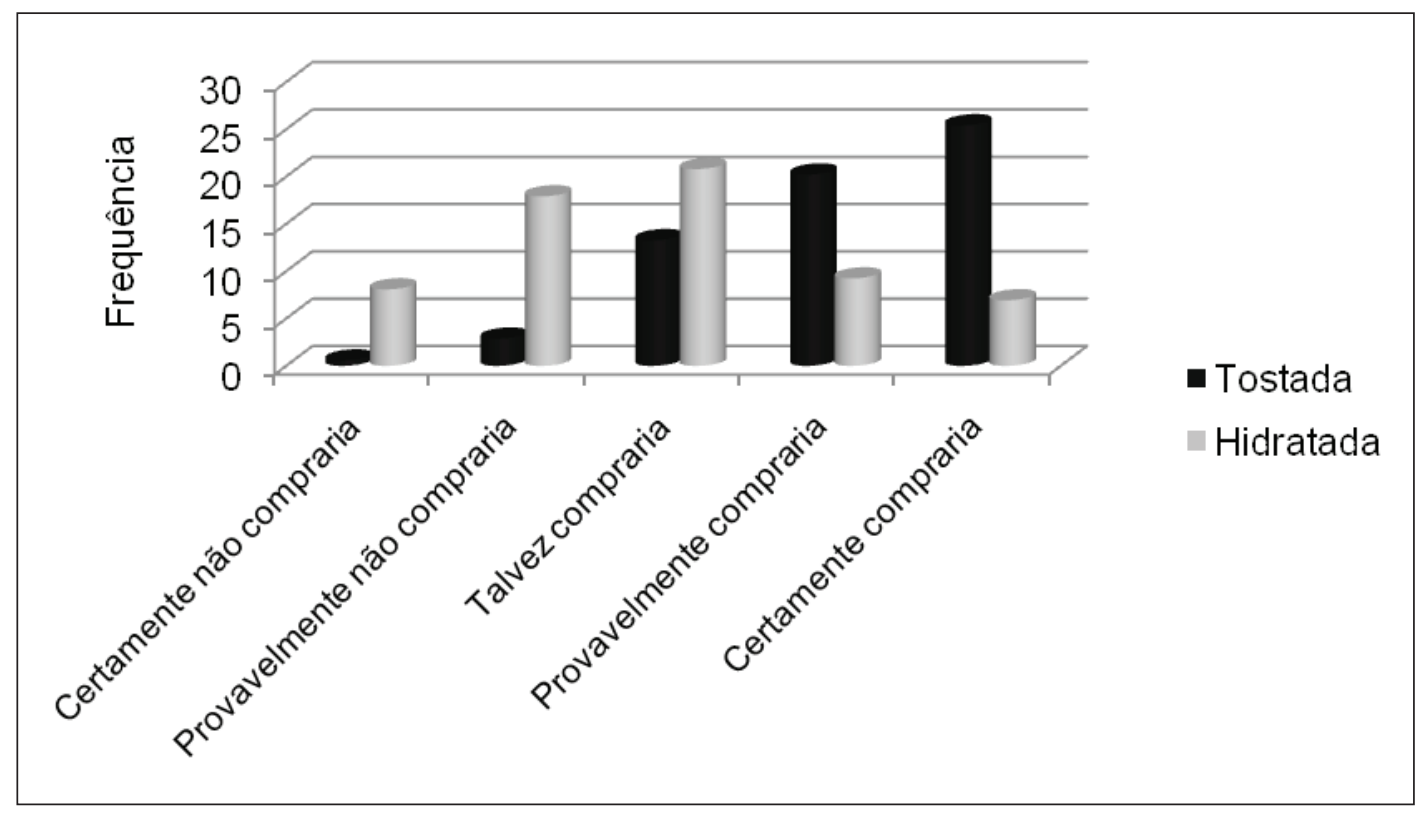

Figura 4. Distribuição da frequência para a intenção de compra da barra de cereal contendo grão de quinoa torrado e hidratado pelos consumidores. Pelotas-RS, 2014.

\section{Discussão}

Ao avaliar a composição centesimal dos grãos de quinoa, observa-se que o teor de proteína e fibra bruta não foi afetado pelo processamento térmico. Já o teor de cinzas reduziu no grão hidratado, o que pode ter ocorrido devido à perda de sais minerais na água de hidratação, que foi descartada. O teor lipídico diferiu estatisticamente entre os processamentos, sendo superior no grão hidratado. Esse aumento no teor lipídico também foi encontrado por Moura et al..$^{14} \mathrm{em}$ 
grãos de soja submetidos a diferentes tratamentos térmicos. Supõe-se que isso aconteça devido à alteração na estrutura química do grão quando é submetido ao aquecimento, no qual o componente lipídico se liga fortemente ao amido, expressando-o junto na extração.

Quanto às barras de cereal, o valor de umidade diferiu significativamente entre a barra contendo quinoa torrada e a contendo quinoa hidratada. A barra formulada com grãos torrados apresentou conteúdo de umidade relativamente baixo, estando de acordo com a legislação vigente, que determina umidade para barra de cereal inferior a 15,0\%, já a barra contendo grãos hidratados apresentou umidade acima do estabelecido pela legislação. ${ }^{15}$ Elevados teores de umidade podem acelerar a deterioração do produto devido à maior disponibilidade de água para as reações químicas e microbiológicas.

O teor proteico diferiu entre as duas barras, sendo maior na elaborada com grãos hidratados. Pode ser que no momento da análise tenha sido retirada uma amostra com maior conteúdo de castanha, influenciando nesse resultado, já que os processamentos não afetaram o teor de proteínas nos grãos e as barras foram elaboradas com os mesmos ingredientes, alterando apenas o grão processado. A quantidade de proteína das duas barras foi superior ao encontrado por Rodrigues et al. ${ }^{16} \mathrm{em}$ barras de cereal comercializadas na cidade de Cascavel-PR, que apresentaram em média $5,07 \%$ desse nutriente e semelhante ao conteúdo proteico de barras de cereal desenvolvidas com grão de quinoa cru e farinha de quinoa, conforme estudo de Silva et al. ${ }^{3}$ Porém, menor que o valor proteico encontrado por Baú et al. ${ }^{17}$ em barras de cereais à base de proteína de soja texturizada e aveia contendo $15,8 \%$ de proteína.

Comparando as amostras, a barra contendo grãos de quinoa hidratados apresentou maior teor proteico que a barra com grãos torrados, e menor teor de cinzas devido à perda na água de hidratação. Cabe ressaltar que a quinoa é o único alimento vegetal capaz de fornecer todos os aminoácidos essenciais e sua proteína é comparada à caseína, proteína de alto valor biológico do leite. ${ }^{18}$ Outro fator positivo é que o grão é isento de glúten, assim como todos os outros ingredientes utilizados na formulação da barra, podendo ser consumida por portadores de doença celíaca. ${ }^{19}$

Em nosso estudo, as barras de cereal tiveram $40 \%$ de sua composição baseada em quinoa, isso agrega um valor nutritivo e benéfico ao produto, pois no estudo de Farinazzi-Machado et al., ${ }^{20}$ que utilizou barra de cereal contendo 39\% de quinoa e avaliou o efeito no perfil bioquímico, antropométrico e de pressão arterial em humanos (parâmetros de fatores de risco para doenças cardiovasculares), tratados durante 30 dias, verificou-se redução significativa nos valores de colesterol total, triglicerídeos e LDL-c, indicando que o uso da quinoa na alimentação pode ser considerado benéfico na prevenção desses fatores de risco. Isso pode ser devido ao seu teor de vitamina E, polifenóis, fitoesteróis e flavonoides, compostos que possuem capacidade antioxidante e podem estar relacionados com a redução de lipídios plasmáticos encontrados nesses indivíduos. ${ }^{21}$ 
Por meio da análise sensorial, observa-se que os consumidores preferiram a barra com quinoa torrada, que apresentou notas superiores à barra com quinoa hidratada em todos os atributos, obtendo assim um bom índice de aceitabilidade (85\%), enquanto a barra contendo grãos hidratados não foi bem aceita pelos consumidores (66,34\%). Para que seja considerado aceito é necessário que o produto obtenha índice de aceitabilidade (IA) de no mínimo $70 \% \cdot{ }^{13} \mathrm{O}$ atributo determinante para a baixa aceitação da barra hidratada foi a textura, isso pode ser comprovado pelas baixas notas obtidas e também por comentários deixados pelos consumidores na ficha de avaliação, caracterizando essa barra com "textura amolecida" e "não condiz com textura de barra de cereal”. Já os comentários referentes à textura da barra torrada foram em geral "textura crocante". Além disso, comprova-se a preferência pela barra torrada, que além de apresentar maior IA, obteve comentários positivos também nos outros atributos, como "apresenta melhor cor" e "sabor adocicado".

Comparando com outros estudos, a aceitação da barra de cereal com grãos torrados foi menor que a encontrada por Silva et al. ${ }^{3}$ em barras também contendo quinoa (95\%). Porém, foi maior ao verificado por Rutz et al. ${ }^{22}$ em barra elaborada com torta de amendoim e soja, que obteve IA de $77,86 \%$, e por Costa et al., ${ }^{23}$ que encontrou IA de 81,33\% para barra de cereal à base de resíduo da fabricação de farinha de mandioca.

A maioria dos consumidores indicou que "certamente e provavelmente comprariam" a barra de cereal desenvolvida com grãos de quinoa torrados, porém "provavelmente não comprariam" ou "talvez comprariam" a barra desenvolvida com grãos hidratados, demonstrando que a melhor formulação para a barra de quinoa seria com os grãos torrados.

\section{Conclusão}

Considerando a preferência e maior intenção de compra pela barra de quinoa com grãos torrados em relação à barra de quinoa contendo grãos hidratados, conclui-se que a formulação contendo grão tostado é a mais adequada para desenvolvimento do produto, o qual possui viabilidade para comercialização. O elevado teor nutricional da quinoa, com ênfase para o seu teor proteico, agrega qualidade a essa barra de cereal, que representa uma opção de lanche rápido para os consumidores.

\section{Referências}

1. Capriles VD, Arêas JAG. Barras de amaranto enriquecidas com frutanos: aceitabilidade e valor nutricional. ALAN 2010; 60(3):291-297.

2. Freitas GCD, Moretti HR. Barra de cereais de elevado teor proteico e vitamínico: estabilidade enzimática e das vitaminas C e E durante armazenamento [Internet]. ALAN 2006; 56(3). Disponível 
em: http://www.scielo.org.ve/scielo.php?script=sci_arttext\&pid=S0004-06222006000300010

3. Silva FD, Pante CF, Prudêncio SH, Ribeiro AB. Elaboração de uma barra de cereal de quinoa e suas propriedades sensoriais e nutricionais. Alim Nutr. 2011; 22(1):63-69.

4. Jacobsen SE. The worldwide potential for quinoa (Chenopodium quinoa Willd.). Food Rev Int. 2003; 19:167-177.

5. Stikic R, Glamoclija D, Demin M, Vucelic-Radovic B, Jovanovic Z, Milojkovic-Opsenica D, et al. Agronomical and nutritional evaluation of quinoa seeds (Chenopodium quinoa Willd.) as an ingredient in bread formulations. J Cereal Sci. 2012; 55:132-138.

6. Miranda M, Vega-Gálvez A, Quispe-Fuentes I, Rodríguez MJ, Maureira H, Martínez EA. Nutritional aspects of six quinoa (Chenopodium quinoa Willd.) ecotypes from three geographical areas of Chile. Chilean J. Agric Res. 2012; 72(2):175-181.

7. Kumpun S, Maria A, Crouzet S, Todeschi NE, Girault JP, Lafont R. Ecdysteroids from Chenopodium quinoa Willd, an ancient Andean crop of high nutritional value. Food Chem. 2011; 125: 1226-1234.

8. Borges JT, Bonomo R, Paula CD, Oliveira LC, Cesário MC. Características físico-químicas, nutricionais e formas de consumo da quinoa (Chenopodium quinoa Willd.). Revista Temas Agrários 2010; 15(1):9-23.

9. Pedrão MR, Coró FAG. Análise sensorial e sua importância na pesquisa de alimentos. UNOPAR Cient Ciênc Biol Saúde 1999; 1(1):85-89.

10. Teixeira KR. Análise sensorial. SBRT. Minas Gerais: CETEC; 2007.

11. Instituto Adolfo Lutz. Métodos físico-químicos para análise de alimentos. 4 ed. São Paulo: IDF; 2008.

12. United States Departament of Agriculture. Composition of foods: baby foods, raw, processed, prepared. Washington. D.C.: Agricultural Research Center Service; 1963. (Agriculture handbook, 8-3).

13. Gularte MA. Manual de análise sensorial de alimentos. Pelotas: Universidade Federal de Pelotas; 2009. 105 p.

14. Moura NC, Canniatti-Brazaca SG, Souza MC, Dias CTS. Composição de cultivares de soja submetida a diferentes tratamentos térmicos. Alim Nutr. 2007; 18(2):151-160.

15. Brasil. Resolução RDC nº 263, de 22 de setembro de 2005. Aprova o Regulamento Técnico para Produtos de Cereais, Amidos, Farinhas e Farelos. Diário Oficial da União 23 set. 2005.

16. Rodrigues ML, Fiorese F, Júlio TSK, Lira RK. Controle de qualidade e análise centesimal de uma barra de cereal, comercializada na cidade de Cascavel, PR. Cultivando o Saber 2011; 4(1):36-44.

17. Baú TR, Cunha MAA, Cella SM, Oliveira ALJ, Andrade JT. Barra alimentícia com elevado valor proteico: formulação, caracterização e avaliação sensorial. RBTA 2010; 4(1):42-51.

18. Regional Office for Latin America and the Caribbean. Quinoa: an ancient crop to contribute to world food security. FAO; 2011. 55 p.

19. Jancurova M, Minarovicova L, Dandar A. Quinoa: a review. Czech J Food Sci. 2009; 27(2):71-79. 
20. Farinazzi-Machado FMV, Barbalho SM, Oshiiwa M, Goulart R, Pessan OJ. Use of cereal bars with quinoa (Chenopodium quinoa W.) to reduce risk factors related to cardiovascular diseases. Food Sci Technol. 2012; 32(2):239-244.

21. Abugoch James LE. Quinoa (Chenopodium quinoa Willd.): composition, chemistry, nutritional, and functional properties. Adv Food Res. 2009; 58:1-31.

22. Rutz JK, Voss G, Machado MRG, Rodrigues RS. Elaboração de alimento em barra à base de torta residual da extração do óleo de amendoim por prensagem. Boletim do CEPPA 2011; 29(2):173-180.

23. Costa LA, Bramorski A, Silva MC, Teixeira E, Amboni RDMC. Desenvolvimento de alimento em barra à base de resíduo da fabricação de farinha de mandioca. Alim Nutr. 2005; 16(4):389-396.

Recebido: 08/4/2016

Revisado: 20/7/2016

Aceito: 17/8/2016 